\title{
What Are Students' Perceptions of Retailing as a Career Choice?
}

\author{
Safiek Mokhlis \\ School of Maritime Business and Management \\ Universiti Malaysia Terengganu \\ E-mail: safiek@umt.edu.my
}

Doi:10.5901/ajis.2014.v3n1p363

\begin{abstract}
Retail firms look to graduates as a source for managers of the future. However, negative perceptions among graduates towards working in retailing may result in the industry's failure to attract and retain the most qualified employees. The purpose of this study is to examine the perceptions of current undergraduate students in Malaysia toward a career in retailing. A quantitative methodology, using responses given by 271 undergraduate marketing students, is employed in the analysis. From the results it is clear that students generally have a relatively unfavorable image of retailing as a career.
\end{abstract}

Keywords: perceptions, undergraduates; retailing; career choice

\section{Introduction}

In line with global development, Malaysia's retail landscape has experienced considerable transformation since mid1990s. The liberalization of retail sector and the impressive growth of the economy has attracted huge investments from major international retailers, replacing many local players from the leading positions within the sector. As in August 2013, a total of 189 foreign hypermarkets, superstores, and departmental stores were operating in Malaysia (Ministry of Finance, 2013). The increasing presence of large-scale foreign retailers has changed the structure as well as the competition environment of the domestic market. Factors such as the rise of consumerism, rapid urbanization, rising consumer affluence, the emergence of new retail concepts, technological advancement, and demographic changes, are likely to stimulate the growth of retail sector further in the coming years.

The increasingly competitive pressures called for a greater degree of strategic planning, implementation and business awareness (Helms, Haynes, \& Cappel, 1992) and, as managerial skills become crucial for retail firms to achieve success in a competitive business environment, there has been an increase in the demand for managerial professionals by the retail industry (The Star, 2012). Having a skilled, enthusiastic and motivated workforce is seen as vital to the success of firms in today's competitive business environment (Bartlett \& Ghoshal, 2002). It has been argued that without employees having a positive attitude towards their work, there is minimal chance for the firms to achieve customer satisfaction and loyalty (Harter, Schmidt, \& Hayes, 2002). This is becoming even more evident as increasing competition within the industry has led to organizations using employees as a means of gaining competitive advantage over rivals (Pfeffer, 2005).

An obvious way to build competitive advantage through employee is to attract more graduates into the retailing industry. Recruiting future retail professionals from the existing pool of graduates has become a major goal of many retail businesses. However, the attraction of prospective employees remains a key retailing issue (Broadbridge, 2003b; Rahim, 2012). As a career option, retailing is regarded as having negative associations relative to other career options (Swinyard, 1981; Swinyard, Langrehr, \& Smith, 1991; Broadbridge, 2003a, 2003b). Students appear to associate a career in retailing as predominantly store-based and this is attributed with negative descriptors such as dull, routine and poor working hours (Swinyard et al. 1981; Swinyard et al. 1991). Because of misperceptions, many graduates who possess the ability to become successful in retail profession may select other careers. Of those graduates who enter the industry, it is contended that many soon decide not to pursue a full time, long term career in the industry (Broadbridge, Maxwell, \& Odgen, 2007). The high voluntary turnover rates among graduate employees could potentially result in the rising costs of recruiting, training and retaining talented employees.

To add to the issues facing the retailing industry in attracting graduates, retail recruiters are faced with difficulties in understanding today's students - known as Generation Y who were born after 1980. As a cohort group, this millennial generation has high expectations, an entitlement mentality, and desire greater work/life balance than previous 
generations (Broadbridge, Maxwell, \& Odgen, 2009). Today's student has lower levels of loyalty to future employers and has no hesitancies in jumping ship should a more attractive opportunity come their way (Martin, 2005). Recruiting millennial generation students with potential negative perceptions of retail careers may be a significant issue for marketing educators and retail recruiters.

The purpose of this research was to examine the perceptions of undergraduate students in Malaysia toweards retailing as a career choice. In order that comparisons could be made with previous similar research (Swinyard, 1981; Swinyard et al. 1991; Broadbridge, 2003b), the objectives of the study were to: (1) assess the perceptions of students with respect to the relative appeal of retailing as a career versus the appeal of alternate career options; and (2) identify attributes students desire with regard to their career and measure their perceptions of retail careers.

\section{Methodology}

This study employed a quantitative approach through the use of self-administered, anonymous questionnaire survey. A quantitative approach and questionnaires were considered the most appropriate method for data collection as it allowed for a systematic collection of quantifiable data on a set of pre-determined variables. At the same time, it enabled the maximization of responses. Questionnaire items were developed from a detailed review of variables used in previous studies (Swinyard, 1981; Swinyard et al. 1991; Broadbridge, 2003b), with the intention of replication where possible to aid in comparison of the results.

The questionnaire was administered to selected classes of undergraduate marketing students at one public university in Malaysia. Lecturers were asked to administer the questionnaire during class. Students completed the questionnaires in the lecture and returned them to the lecturer. This collection method resulted in 330 completed surveys, 271 of which were usable. The effective usable response rate of usable surveys, therefore, was 82 per cent. This relatively high response rate was attributed to the self-administered approach undertaken in distributing questionnaires. The data were analyzed using SPSS. Univariate and bivariate analysis was performed on the data and comparisons with previous research findings were drawn.

\section{Results}

Within the sample, 80.1 per cent were female. Their ages ranged from 20 to 33, the mean age being 22.3 years. With regard to race, the largest proportion of the respondents was Malays, accounting for 69.7 per cent of the total sample. The majority of students were in second year (40.2 per cent), 35 per cent were in third year, and 24.7 per cent in first year. 32.1 per cent students had taken retail management course.

Respondents were asked to indicate the appeal of each of the 16 possible career areas, including retailing. Appeal were measured using a five-point Likert scale, ranging from 'very appealing' (1) to 'very unappealing' (5). The students' evaluations of the appeal of the 16 proposed career areas are presented in Table 1 . In contrast to the findings of Swinyard $(1981,1991)$ and Broadbridge $(2003 b)$, the results show that retailing was ranked in ninth of the 16 career areas - lower than all other marketing positions except for market research, industrial sales and real estate. Careers in marketing management, finance, production management, public relations, government service, management consultancy, consumer product sales and accounting were all perceived as more appealing than a career in retailing. The low choices for non-business careers (law and engineering) should not be surprising since the sample respondents were marketing students.

Table 1. Student Evaluations of Career-Area Appeal.

\begin{tabular}{|l|c|c|c|c|c|c|}
\hline \multirow{2}{*}{ Career-area } & \multirow{2}{*}{ Mean } & \multicolumn{5}{c|}{ Percentage of students rating each area } \\
\cline { 3 - 7 } & & Very appealing & Somewhat appealing & Neutral & Somewhat unappealing & Very unappealing \\
\hline Marketing management & 1.73 & 45.8 & 40.2 & 9.6 & 4.4 & 0 \\
Finance & 2.37 & 28.9 & 26.7 & 27.4 & 13.0 & 4.1 \\
Production management & 2.39 & 17.3 & 37.6 & 34.7 & 9.2 & 1.1 \\
Public relations & 2.44 & 12.9 & 42.8 & 33.9 & 8.5 & 2.8 \\
Government service & 2.48 & 24.1 & 27.0 & 30.4 & 13.7 & 4.8 \\
Management consultancy & 2.49 & 12.5 & 37.6 & 40.2 & 7.7 & 2.8 \\
Consumer product sales & 2.54 & 16.7 & 32.6 & 33.3 & 15.2 & 2.2 \\
Accounting & 2.60 & 27.2 & 22.0 & 24.3 & 16.8 & 9.7
\end{tabular}




\begin{tabular}{|l|c|c|c|c|c|c|} 
Retailing & 2.64 & 13.7 & 32.5 & 32.8 & 18.5 & 2.6 \\
Teaching & 2.64 & 23.6 & 22.5 & 28.8 & 16.6 & 8.5 \\
Personnel & 2.65 & 10.3 & 32.8 & 42.1 & 11.4 & 3.3 \\
Market research & 2.65 & 14.8 & 29.2 & 34.7 & 18.8 & 2.6 \\
Industrial sales & 2.89 & 7.7 & 26.2 & 39.5 & 22.5 & 4.1 \\
Real estate & 3.05 & 10.4 & 21.9 & 30.7 & 26.3 & 10.7 \\
Law & 3.36 & 5.9 & 15.5 & 29.5 & 35.1 & 14.0 \\
Engineering & 3.44 & 9.2 & 14.8 & 23.2 & 28.0 & 24.7 \\
\hline
\end{tabular}

1 = Very Appealing; 2 = Somewhat Appealing; 3 = Neutral; 4 = Somewhat Unappealing; 5 = Very Unappealing

As can be seen in Table 2, although 46.2 per cent of the respondents in the current study found the notion of a career in retailing to be somewhat appealing or very appealing, on average students in this survey remain neutral about pursuing a career in retailing. While the average rating of retailing as a career area was 2.67 in Swinyard's (1981) study, 2.98 in Swinyard et al.'s (1991) study, and 2.99 in Broadbridge's (2003b) study, in the current study the average rating of retailing as a career area was only 2.64 .

Table 2. Evaluations of Retailing as a Career Compared with Previous Research.

\begin{tabular}{|l|c|c|c|c|}
\hline \multicolumn{1}{|c|}{ Rating } & Swinyard (1981) & Swinyard et al. (1991) & Broadbridge (2003) & Current study (2014) \\
\hline Very appealing & $16.5 \%$ & $11 \%$ & $9.9 \%$ & $13.7 \%$ \\
Somewhat appealing & $33.1 \%$ & $27.1 \%$ & $26 \%$ & $32.5 \%$ \\
Neutral & $25.3 \%$ & $26.5 \%$ & $28.7 \%$ & $32.8 \%$ \\
Somewhat appealing & $16.9 \%$ & $23.4 \%$ & $25.7 \%$ & $18.5 \%$ \\
Very unappealing & $8.1 \%$ & $12 \%$ & $9.7 \%$ & $2.6 \%$ \\
No response & 11 & 5 & 7 & 0 \\
Average ratings & 2.67 & 2.98 & 2.99 & 2.64 \\
Mean-based ranking & 7 & 7 & 5 & 9 \\
\hline
\end{tabular}

To evaluate whether the appeal of retailing as a career differed across demographic groups and academic performance, one-way analysis of variance was performed. The results are presented in Table 3 . In contrast to the findings of Broadbridge (2003b), the results show that males found retailing to be more appealing than females. Malays found retailing to be more appealing than non-Malays. The more academically able students (i.e. those with higher CGPA) rated retailing as less appealing than those with lower grades, a finding similar to those of Swinyard (1981) and Swinyard et al. (1991), indicating that retail companies may not be attracting the top performing students. As found by Swinyard (1981) and Broadbridge (2003b), those students who had taken a retail course were more likely to considered retailing to be more appealing than those who had not taken a course. Age and year of study were not found to show any significant difference in the appeal of retailing as a career.

Table 3. Appeal of Retailing by Demographic Variables and Academic Performance.

\begin{tabular}{|l|c|c|c|}
\hline \multicolumn{1}{|c|}{ Characteristic } & Number & Mean & $\begin{array}{c}\text { Sig. } \\
\text { (p-value })\end{array}$ \\
\hline Sex & 54 & 2.41 & 0.062 \\
Male & 217 & 2.70 & \\
Female & 85 & 2.74 & n.s. \\
\hline Age group & 78 & 2.71 & \\
$19-20$ & 66 & 2.61 & \\
$21-22$ & 189 & 2.56 & 0.056 \\
$23+$ & 82 & 2.82 & \\
\hline Race & & & \\
Malay & 67 & 2.67 & n.s. \\
Non-Malay & 109 & 2.72 & \\
\hline Year of study & 95 & 2.52 & \\
First year & & & \\
Second year & & & \\
Third year & & & \\
\hline Academic performance & 365 & &
\end{tabular}




\begin{tabular}{|l|c|c|c|} 
CGPA $2.00-2.99$ & 117 & 2.51 & 0.035 \\
CGPA 3.00-4.00 & 92 & 2.80 & \\
\hline Retail course & & & \\
Taken a retail course & 87 & 2.48 & 0.086 \\
Not taken a retail course & 183 & 2.71 & \\
\hline
\end{tabular}

n.s. $=$ not significant at 0.1 level.

Students in the current study were asked to indicate on a five-point Likert scale the extent to which they agreed or disagreed that each attribute was associated with their preferred career. Later in the questionnaire they were asked to do this again, only when thinking about a career in retailing. Table 4 shows the responses to a five-point Likert scale question asking students to rate attributes of their preferred career and a career in retailing. The mean scores for each of the 30 attributes was calculated, revealing that seven were ranked with a mean of 2.0 or less (.i.e. showing broad student agreement that they were perceived as quite or very important to their career choice). As may be expected, students were significantly more likely to rate the positive attributes associated most closely with the students' preferred career over a career in retailing, but to rate the negative attributes for a career in retailing over their preferred career. In particular, the top five attributes associated most closely with the students' preferred career were 'interesting', 'opportunities for advancement', 'good salary', 'challenging' and 'rewarding', similar to those found in Broadbridge's (2003b) study. In comparison, retailing was associated with more neutral or negative attributes than the preferred career, and complied with the research by Swinyard (1981), Swinyard et al. (1991), and Broadbridge (2003b). The top five attributes associated most closely with a career in retailing were 'consumer oriented', 'people oriented', 'routine', 'mundane' and 'hectic'. All of these attributes were included within Broadbridge's (2003a) top 15 attributes associated with a career in retailing.

A series of paired-samples t-test was run to evaluate where mean of preferred career differed significantly from mean of a retail career. The null hypothesis is that the difference in the mean values is zero. A significant difference is found if an alpha level ( $p$-score) is less than the critical value of 0.05 . As can be seen in Table 4 , the majority of the attributes are seen to be significantly different $(p<0.05)$. The eight attributes that are not significantly different are 'exciting', 'management responsibility', 'changing, dynamic', 'hard work', 'competitive', 'require me to be mobile', 'opportunity to use initiative', and 'prestige/status oriented'. In each of the twelve positive attributes that are significantly different the preferred career has a lower mean than the retail career. For the rest of ten attributes that are significantly different, the retail career has a lower mean than the preferred career. With the exception of 'consumer oriented' and 'people oriented', all of these attributes may be regarded as negatives.

The attributes towards a career in retailing in Table 4 were tested to see if there were any significant differences between the responses of students who had taken a retail course $(n=87)$ and those who had not $(n=183)$. Only four of the 30 attributes used to describe a career in retailing showed significant differences. Students who had taken a retail course were significantly more likely than others to believe that retailing is more dynamic $(t=-3.368 ; p=0.001)$, offers a good salary $(t=-2.154 ; p=0.032)$, diversified work $(t=-2.19 ; p=0.029)$ but limited advancement $(t=-2.227 ; p=$ 0.027). Overall, however, taking a retail course did not significantly affect students' ratings of the majority of attributes.

Table 4. Attributes of Most Preferred Career and a Career in Retailing.

\begin{tabular}{|l|c|c|c|c|}
\hline \multicolumn{1}{|c|}{ Attribute } & Mean of preferred career & Mean of retail career & t-value & $\begin{array}{c}\text { Sig. } \\
\text { (2-tailed) }\end{array}$ \\
\hline Interesting & 1.44 & 2.20 & -12.716 & 0.000 \\
Challenging & 1.64 & 2.07 & -6.715 & 0.000 \\
Opportunities for advancement & 1.45 & 2.00 & -9.742 & 0.000 \\
A good salary & 1.64 & 2.29 & -10.334 & 0.000 \\
Consumer oriented & 2.10 & 1.69 & 5.978 & 0.000 \\
Exciting & 2.20 & 2.29 & -1.593 & 0.112 \\
Rewarding & 1.73 & 2.33 & -9.023 & 0.000 \\
Creative & 1.96 & 2.24 & -3.770 & 0.000 \\
Independent & 2.01 & 2.29 & -3.669 & 0.000 \\
Diversified work & 2.11 & 2.25 & -2.081 & 0.038 \\
Management responsibility & 1.96 & 1.96 & -0.051 & 0.959 \\
Prestigious & 2.17 & 2.61 & -6.689 & 0.000 \\
Satisfying & 2.07 & 2.50 & -7.081 & 0.000 \\
& -0.5 & & &
\end{tabular}




\begin{tabular}{|c|c|c|c|c|c|}
\hline Changing, dynamic & 2.30 & 2.40 & -1.447 & 0.149 & n.s. \\
\hline Hard work & 2.10 & 2.16 & -0.784 & 0.433 & n.s. \\
\hline Unsociable hours & 3.44 & 3.15 & 3.476 & 0.001 & \\
\hline People oriented & 2.35 & 2.13 & 3.398 & 0.001 & \\
\hline Routine & 3.00 & 2.57 & 5.173 & 0.000 & \\
\hline Mundane & 3.38 & 2.85 & 7.302 & 0.000 & \\
\hline Competitive & 2.45 & 2.39 & 0.761 & 0.447 & n.s. \\
\hline Hectic & 2.94 & 2.63 & 4.080 & 0.000 & \\
\hline Opportunities for training and development & 2.04 & 2.26 & -3.287 & 0.001 & \\
\hline Require me to be mobile & 2.02 & 2.07 & -0.632 & 0.528 & n.s. \\
\hline Physically demanding & 2.75 & 2.29 & 5.842 & 0.000 & \\
\hline Opportunity to use initiative & 2.35 & 2.38 & -0.288 & 0.774 & n.s. \\
\hline Poor salary & 4.28 & 3.61 & 10.414 & 0.000 & \\
\hline Poor working hours & 4.05 & 3.42 & 9.143 & 0.000 & \\
\hline Prestige/status oriented & 2.94 & 2.99 & -0.716 & 0.475 & n.s. \\
\hline Limited advancement & 3.94 & 3.25 & 8.451 & 0.000 & \\
\hline Degree related & 2.06 & 2.38 & -4.263 & 0.000 & \\
\hline
\end{tabular}

Note: 1 = Strongly Agree; 5 = Strongly Disagree, n.s. = not significant at 0.05

\section{Conclusions}

Perceptions toward retailing as a career can be a good predictor of students' career selection behaviors. The main findings of this study concur with those of Swinyard (1981), Swinyard et al. (1991) and Broadbridge (2003a, 2003b) who all found that students generally have a relatively unfavorable image of retailing as a graduate career. In analyzing the findings of this study the first noticeable fact was that whilst 46.2 per cent find it in any way appealing, the average rating of retailing as a career area was only 2.64 and it was ranked in ninth of the 16 career areas. Students' evaluations of retailing as a career were found to be significantly affected by their gender, race, overall academic performance and their enrollment in a retail course. This study has also found that students who are studying marketing in Malaysia do not believe that the industry offers them the attributes that they see as important in choosing a future career. It was found, that for the majority of the 30 factors examined, there is a significant difference between what the students see as important in determining their career choice and the extent to which they believe a career in retailing offers these.

The results of this research suggest several implications for marketing educators and retail recruiters. Marketing educators can play their role by giving all prospective students an extensive overview of the types of careers available in the retail industry and its working conditions, as well as pay levels, promotion opportunities and career paths on offer. In order to minimize the gap between expectations and perceptions, students need to be informed about employment opportunities and conditions, prior to beginning their academic program. By giving students realistic information about a career in the industry they would form more realistic and lower expectations of subsequent employment. This will help reduce the number of graduates who develop negative attitudes towards a career in the industry, as they will be more informed about the reality of working in the industry (Broadbridge, 2003b).

Retail firms must continue to work on improving many aspects of the working conditions within the industry. There are a number of areas that students believe the industry is behind other industries, particularly in regards to pay, opportunities for advancement, training and development, and working hours. If the industry can address concerns in these areas it will help to clear up the misconceptions of students regarding the job characteristics that are associated with people employed by retail firms. Hopefully this will help to maximize the number of university graduates entering and remaining in the industry.

The results of this study are useful; however, some limitations of this study should be acknowledged. The sample was comprised of students from only one public university; these respondents are probably not representative of student population in Malaysia, thus reducing the generalizability of the results. Large sample sizes can be utilized in future studies to increase generalizability of the findings. Another limitation is the fact that the students surveyed were marketing students. Surveying more non-marketing majors may provide a shaper and more delineated indication of what the real perceptions are of divergent groups. Future studies must also explore students' perceptions toward different retail jobs or their preferences to work in different retail sectors. 


\section{References}

Bartlett, C. A. \& Ghoshal, S. (2002). Building competitive advantage through people. MIT Sloan Management Review, 43(2), 34-41.

Broadbridge, A. (2003a). Student perceptions of retailing as a destination career. International Journal of Retail \& Distribution Management, 31(6), 298-309.

Broadbridge, A. (2003b). The appeal of retail as a career 20 years on. Journal of Retailing and Consumer Services, 10, $287-296$.

Broadbridge, A. M., Maxwell, G. A. \& Ogden, S. M. (2007). 13_2_30: Experiences, perceptions and expectations of retail employment for Generation Y. Career Development International, 12(6), 523-544.

Broadbridge, A., Maxwell, G. A., \& Ogden, S. M. (2009). Selling retailing to Generation Y graduates: recruitment challenges and opportunities. International Review of Retail, Distribution and Consumer Research, 19(4), 405-420.

Harter, J. K., Schmidt, F. L., Hayes, T. L. (2002). Business-unit-level relationship between employee satisfaction, employee engagement, and business outcomes: a meta-analysis. Journal of Applied Psychology, 87(2), 268-279.

Helms, M. M., Haynes, P. J., \& Cappel, S. D. (1992). Competitive strategies and business performance within the retailing industry. International Journal of Retail \& Distribution Management, 20(5), 3-14.

Martin, C. A. (2005). From high maintenance to high productivity: What managers need to know about Generation Y. Industrial and Commercial Training, 37(1), 39-44.

Ministry of Finance Malaysia (2013). Economic Report 2013/14.

Pfeffer, J. (2005). Producing sustainable competitive advantage through the effective management of people. The Academy of Management Executive, 19(4), 95-108.

Rahim, R. (2012, July 10). Grads turning their backs on retail industry, says MRCA. The Star. Retrieved from http://thestar.com.my/news /story.asp?file=/2012/7/10/nation/11634400\&sec=nation

Rhoads, G. K., Swinyard, W. R., Geurts, M. D., \& Price, W. D. (2002). Retailing as a career: A comparative study of marketers. Journal of Retailing, 78(1), 71-76.

Swinyard, W. R. (1981). The appeal of retailing as a career. Journal of Retailing, 57(4), 86-97.

Swinyard, W. R., Langrehr, F. W., \& Smith, S. M. (1991). The appeal of retailing as a career: a decade later. Journal of Retailing, 67(4), 451-65.

The Star (2012, July 8). A boost for retail sector employees. Retrieved from http://thestar.com.my/education/story.asp?file=\%2F2012 \%2F7\%2F8\%2Feducation\%2F11561482 